\title{
EFEITO DO FOGO NA PRODUÇÃO DE FRUTOS DE Qualea parviflora MART. (Vochysiaceae) EM CERRADO SENSU STRICTO1
}

\author{
Alexandre Cesar Palermo ${ }^{2}$ e Heloisa Sinatora Miranda ${ }^{3}$
}

\begin{abstract}
RESUMO - Entre os muitos efeitos causados por queimadas nas espécies arbóreas nativas do Cerrado, a alteração da produção de frutos tem destaque, pois implica diretamente na manutenção de populações locais. O objetivo deste trabalho foi investigar o efeito de uma queimada prescrita na produção de frutos de Qualea parviflora Mart. em área de Cerrado sensu stricto em Brasília, DF. Foram utilizadas duas áreas de Cerrado sensu stricto, uma submetida a regime de queima bienal em agosto (queimada) e outra protegida contra a queima há 14 anos (controle). Em cada área, 10 indivíduos reprodutivos foram selecionados e a sua produção de botões florais, flores e frutos, acompanhada durante 22 meses. Dois meses após uma queimada prescrita em 26 de agosto de 2008, a produção de estruturas reprodutivas foi maior na área queimada do que na área-controle. Contudo, a proporção de botões que geram flores e frutos ("fruit set") foi a mesma nas duas áreas. Na estação reprodutiva seguinte, um ano após a queima não houve produção de inflorescências na área queimada. No entanto, na área-controle a produção de frutos foi maior do que no período anterior. A ausência de produção de flores nos indivíduos da área queimada um ano após o fogo sugere que $Q$. parviflora pode necessitar de mais de um ano para retornar ao seu ciclo normal de reprodução, indicando que os efeitos de médio e de longo prazo devem ser considerados ao se usar o fogo como instrumento de manejo para redução do combustível em áreas de Cerrado.
\end{abstract}

Palavras-chave: Qualea parviflora, "Fruit set" e Fogo.

\section{EFFECT OF FIRE ON THE FRUIT PRODUCTION OF Qualea parviflora MART. (Vochysiaceae) IN THE CERRADO}

\begin{abstract}
Among the many effects caused by fires on native species of the Cerrado, the change in fruit production has been highlighted, since it results directly in the maintenance of local populations. The objective of this study was to investigate the effect of a prescribed burning on fruit set of Qualea parviflora Mart. in a cerrado sensu stricto area in Brasília-DF. Two areas of cerrado were studied, one submitted to biennial prescribed burnings in August (burned) and one fire protected for 14 years (control). In each area, 10 reproductive individuals were selected and their production of flower buds, flowers and fruits was monitored for 22 months. Two months after the prescribed fire on August 26, 2008, the production of reproductive structures was higher in the burned than in the control area. However, the proportion offlower buds that develop flowers and fruits (fruit set) was the same in both areas. One year after the fire, there was no inflorescence production in the burned area. However, in the control area the yield was higher than in the previous period. The absence offlower production in individuals of the burned area one year after the fire suggest that $\mathbf{Q}$. parviflora may need more than a year to return to a normal cycle of reproduction, indicating that medium and long term effects of fire should be considered when using fire as a management tool to reduce fuel in areas of Cerrado.
\end{abstract}

Keywords: Qualea parviflora, "Fruit set" and Fire.

\footnotetext{
${ }^{1}$ Recebido em 01.03.2011 e aceito para publicação em 28.05.2012.

${ }^{2}$ Universidade de Brasília, Instituto de Ciências Biológicas, Departamento de Ecologia. E-mail: <alexandre.ecofogo@ gmail.com>.

${ }^{3}$ Universidade de Brasília, Instituto de Ciências Biológicas, Departamento de Ecologia. E-mail: <hmiranda@unb.br>.
} 


\section{INTRODUÇÃO}

Dado o seu tempo de coexistência com as comunidades vegetais, o fogo tornou-se fator inerente e de elevada importância ecológica, podendo afetar o estabelecimento, crescimento e reprodução de espécies vegetais (WHELAN, 1995). Em ecossistemas savânicos, como o Cerrado, a ocorrência de queimadas e incêndios provoca mudanças florísticas e estruturais na vegetação (WHELAN, 1995; SATO et al., 1998; MEDEIROS; MIRANDA, 2005). Apesar de não se conhecer a frequência de incêndios naturais no Cerrado, a utilização dessa área para fins agropecuários tem alterado o regime natural de queima, com queimadas sendo atualmente realizadas na estação seca em intervalos de um a quatro anos (COUTINHO, 1982, 1990). Embora várias espécies lenhosas do Cerrado apresentem adaptações contra as altas temperaturas e danos causados pelo fogo (COUTINHO, 1990), queimadas frequentes podem resultar em altas taxas de mortalidade (SATO, 2003; MEDEIROS; MIRANDA, 2005) e menores taxas de recrutamento via mortalidade de plântulas (MIYANISHI; KELMAN, 1986; HOFFMANN, 1998; BRAZ et al., 2000; HOFFMANN; HARIDASAN, 2008) e perda de frutos e sementes (MIRANDA, 1995; LANDIN; HAY, 1996; SCHIMIDT et al., 2005). Ainda que a reprodução vegetativa seja considerada predominante para a vegetação do Cerrado (HOFFMANN, 1998; ANDRADE; MIRANDA, 2010), a reprodução sexuada e o estabelecimento de plântulas são também considerados características comuns (LABOURIAU et al., 1963; MIYANISHI; KELLMAN, 1986; OLIVEIRA; SILVA, 1993; HOFFMANN, 1998; BRAZ et al., 2000; HOFFMANN; HARIDASAN, 2008) e podem ser afetados em curto ou em longo prazo pela passagem da frente de fogo.

Intensa floração pode ser observada após a ocorrência de incêndios ou queimadas (WHELAN, 1995; MAIN; BARRY, 2002; WROBLESKI; KAUFFMAN, 2003; BREWER, 2008). De forma geral, grande parte da literatura relata a floração pós-fogo da vegetação do estrato rasteiro, inclusive no Cerrado (COUTINHO, 1990; HADDAD; VALIO, 1993; MUNHOZ; FELFILI, 2005). Poucos são os trabalhos que reportam a floração de espécies do estrato arbóreo após a ocorrência de queimadas. Esses estudos relatam a rápida floração após a ocorrência de queimadas (FREITAS, 1998), floração mais intensa após o fogo (MIRANDA, 1995; HOFFMANN, 1998; BENEZAR; PESSONI, 2006), estímulo na produção de botões e frutos (SILVA et al., 1996; MIOLA et al., 2010) e antecipação no período de floração (MIOLA et al., 2010). Embora a floração possa ser estimulada, alterações de longo prazo na produção de flores e frutos foram relatadas por Hoffmann (1998) em Miconia albicans, Rourea induta, Myrsine guianensis e Roupala montana que, mesmo três anos após o fogo, apresentaram produção menor que a de indivíduos em área protegida contra o fogo por sete anos. Sanaioti e Magnunsonn (1995) também reportaram redução na produção de flores e frutos de espécies lenhosas um ano após a queimada em áreas de Cerrado, o que pode estar associado a investimento preferencial na reposição de órgãos vegetativos danificados durante a passagem da frente de fogo (HOFFMANN, 1998; MEDEIROS; MIRANDA, 2008). As diferentes respostas da vegetação registradas nesses estudos e o baixo número de espécies estudadas constituem uma lacuna no conhecimento sobre os efeitos do fogo na reprodução de espécies lenhosas do Cerrado necessário para sua utilização como ferramenta de manejo.

Este trabalho teve como objetivo investigar os efeitos do fogo na floração e frutificação de indivíduos de Qualea parviflora Mart. (Vochysiaceae), comparando-se a resposta de indivíduos em área de Cerrado sensu stricto submetida à queimada prescrita em meados da estação seca de 2008 com a de indivíduos em área adjacente protegida contra queimadas por 14 anos.

\section{MATERIAL E MÉTODOS}

\subsection{Espécie estudada}

Qualea parviflora é uma espécie nativa do Cerrado da família Vochysiaceae. Esta família está entre as mais importantes entre as plantas lenhosas, com 36 espécies nesse bioma, sendo, segundo Ribeiro e Haridasan (1984), a mais importante em relação à biomassa aérea no Cerrado sensu stricto. Ocorre em toda a Região Centro-Oeste e nos seguintes Estados: Tocantins, Piauí, Bahia, Minas Gerais e São Paulo (SILVA, 2005). Q. parviflora ocorre nas fitofisionomias de cerradão, Cerrado sensu stricto e campos. Apresenta hábito arbóreo com altura média de $6 \mathrm{~m}$, podendo atingir $15 \mathrm{~m}$, e é uma espécie decídua, perdendo as folhas durante a estação seca, de abril a agosto. Sua floração ocorre no início e decorrer da estação chuvosa, de setembro a dezembro, logo após o começo da brotação das folhas. O padrão de floração consiste na abertura de poucas flores por dia durante longo período de tempo (steady state). As flores são 
hermafroditas, com guia de néctar e antese diurna, sendo abertas em média duas flores por dia, por inflorescência. Os frutos são secos e deiscentes, possuem três lóculos e, em média, uma semente por lóculo (OLIVEIRA; PAULA, 2001) e amadurecem de setembro a outubro (SILVA, 2005; OLIVEIRA; PAULA, 2001). Estudos recentes apontaram que essa espécie possui altos índices de valor de importância em áreas não queimadas (LOPES et al., 2009) e alta mortalidade de indivíduos jovens após a ocorrência de incêndios ou queimadas (FIEDLER et al., 2004). A espécie apresenta altas taxas de recrutamento (AQUINO et al., 2007), o que compensaria a mortalidade e manteria a espécie em posição de destaque na estrutura da comunidade.

\section{2. Área de estudo}

Este trabalho foi realizado na Reserva Ecológica do Instituto Brasileiro de Geografia e Estatística (IBGE), a $36 \mathrm{~km}$ ao Sul de Brasília (156'41' S e 47 53'07' W), Distrito Federal. A reserva possui área de 1.360 ha e está a uma altitude de $1.100 \mathrm{~m}$. O clima é sazonal, apresentando estação seca de maio a setembro e uma estação chuvosa de outubro a abril. Na estação chuvosa ocorrem $90 \%$ da precipitação anual, cerca de $1.483 \mathrm{~mm}$, em média. A temperatura média anual é de $21,9^{\circ} \mathrm{C}$, e o solo predominante é o Latossolo Vermelho-Amarelo, também ocorrendo os Latossolos Vermelho-Escuros (PEREIRA et al., 2004).

Em julho de 2008, duas áreas foram selecionadas para o estudo: a primeira com 10 ha (200 m x $500 \mathrm{~m})$, que vem sendo queimada a cada dois anos desde agosto de 1992, quando se encontrava protegida contra o fogo por 18 anos; e a segunda, adjacente à primeira, com cerca de 5 ha $(50 \mathrm{~m} \times 1.000 \mathrm{~m})$, que estava protegida contra o fogo há 14 anos e foi utilizada como áreacontrole. A primeira área foi utilizada como área experimental, onde foi realizada a queimada prescrita em 26 de agosto de 2008.

\subsection{Acompanhamento da produção de frutos}

Quinze dias antes da queimada de agosto de 2008, foram selecionados e marcados 20 indivíduos reprodutivos de $Q$. parviflora, 10 em cada área. Os indivíduos foram considerados reprodutivos quando possuíam frutos. A produção de botões florais, flores e frutos de $Q$. parviflora foi acompanhada semanalmente durante 22 meses, de outubro de 2008 a agosto de 2010, compreendendo duas estações reprodutivas para avaliar o efeito do fogo na produção de frutos da espécie. A metodologia adotada foi semelhante à apresentada por Silva (1998) em estudo sobre a fenologia de $Q$. grandiflora. Em cada um dos 20 indivíduos selecionados foram marcados três ramos principais, nos quais foram selecionados e marcados três ramos secundários. Cada ramo secundário teve duas inflorescências marcadas, perfazendo 18 inflorescências por indivíduo. As observações foram realizadas a partir do momento em que os botões eram diferenciáveis entre si. A cada novo ciclo reprodutivo, novos ramos secundários e inflorescências foram marcados.

\subsection{Análise estatística}

O número de indivíduos florindo em cada área foi comparado por teste $\mathrm{G}$, enquanto o número de ramos secundários que produziram inflorescências foi comparado por $\mathrm{X}^{2}$, ambos a $5 \%$ de probabilidade. As produções de botões florais, flores e frutos foram comparadas pelo teste não paramétrico de KruskallWallis $(\alpha=0,05)$ e pelo teste de Student-Newman-Keuls, como análise a posteriori.

\section{RESULTADOS}

No período de outubro de 2008 a outubro de 2009, o número de indivíduos de $Q$. parviflora produzindo flores foi significativamente maior $(G=5,2690$; $p<0,05)$ na área submetida à queimada prescrita do que na controle: quatro na área-controle e oito na área queimada. O número de ramos secundários com inflorescências foi maior $\left(\mathrm{X}^{2}=10,123 ; \mathrm{p}<0,05\right)$ na área queimada (34) do que na área-controle (15). A produção de botões florais na área-controle (384) foi significativamente menor ( $\mathrm{p}<0,05$; Figura 1) que na área queimada (2.319). Dos botões iniciados em cada área, 106 resultaram em flores na controle e 635 na queimada. Embora a produção de flores tenha sido significativamente maior $(\mathrm{p}<0,05)$ na área queimada (Figura 2), a conversão de botões em flores foi aproximadamente a mesma (27\%) nas duas áreas. $\mathrm{Na}$ área-controle foram produzidos 90 frutos, enquanto na queimada, 531 (Figura 3). Cerca de cinco meses após o início da floração, houve produção de inflorescências na área experimental, porém não produziram frutos. O total de frutos produzidos nas duas áreas representou aproximadamente $23 \%$ dos botões iniciados e $84 \%$ das flores (Tabela 1). Embora a proporção de botões que resultam em frutos seja semelhante nas duas áreas, a produção de frutos foi significativamente maior $(\mathrm{p}<0,05)$ na área queimada (34) do que na controle.

Revista Árvore, Viçosa-MG, v.36, n.4, p.685-693, 2012 


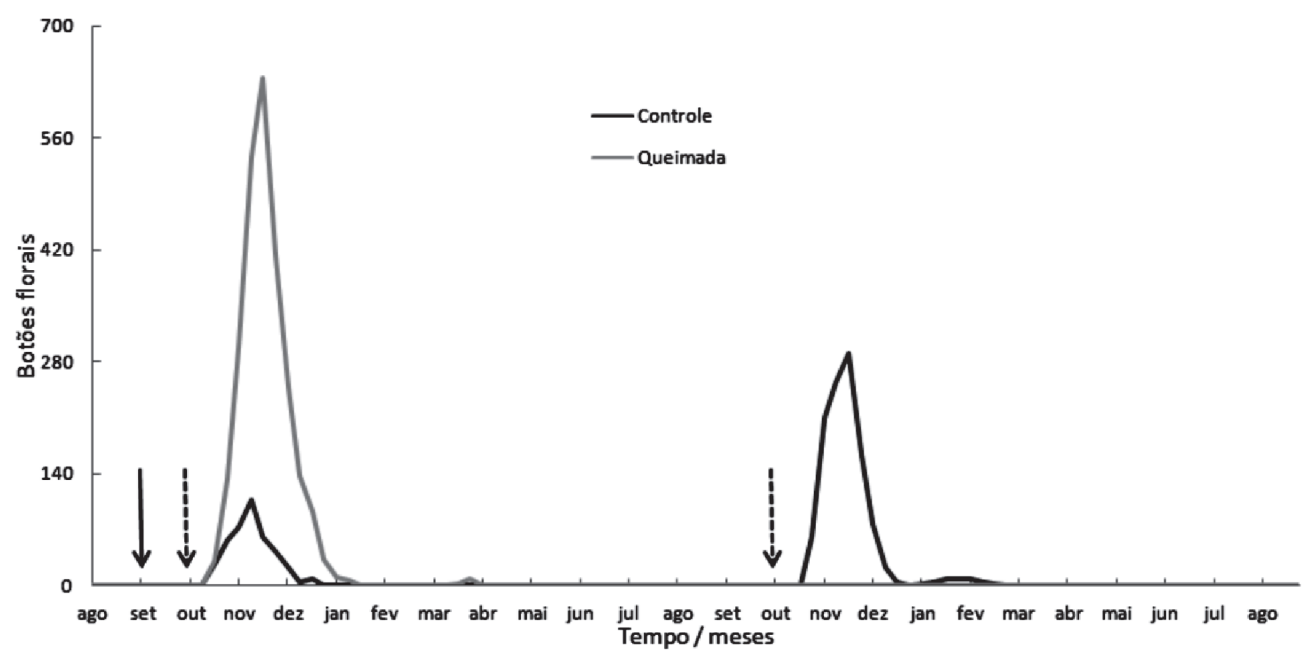

Figura 1 - Produção de botões florais de Qualea parviflora de agosto de 2008 a agosto de 2010, em área de Cerrado sensu stricto protegida contra queima por 14 anos (controle) e em área submetida à queimada prescrita em 26 de agosto de 2008 (queimada), na Reserva Ecológica do IBGE, Brasília, DF. A queima está representada pela seta preta e o início da estação chuvosa $(>10 \mathrm{~mm})$ em cada período, representado pelas setas pontilhadas.

Figure 1 - Production of floral buds of Qualea parviflora from August 2008 to August 2010 in cerrado sensu stricto protected against fire for 14 years (control) and in cerrado sensu stricto submitted to a prescribed burning on August 26, 2008 (burned) in the Reserva Ecológica do IBGE, Brasília-DF. The prescribed burning is represented by the black arrow and the beginning of the rainy season $(>10 \mathrm{~mm})$ in each period is represented by dashed arrows.

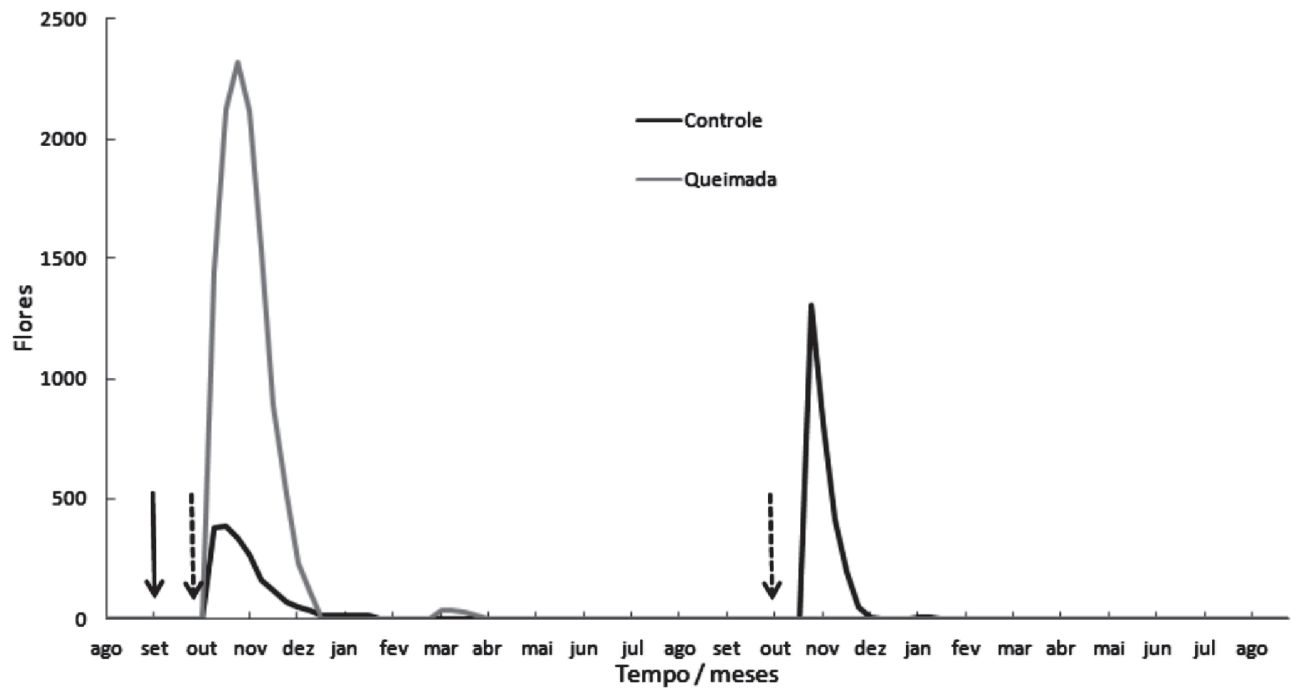

Figura 2 - Produção de flores de Qualea parviflora de agosto de 2008 a agosto de 2010, em área de Cerrado sensu stricto protegida contra queima por 14 anos (controle) e em área submetida à queimada prescrita em 26 de agosto de 2008 (queimada), na Reserva Ecológica do IBGE, Brasília, DF. A queima está representada pela seta preta e o início da estação chuvosa ( $>10 \mathrm{~mm}$ ) em cada período, representado pelas setas pontilhadas.

Figure 2 - Flower production of Qualea parviflora from August 2008 to August 2010 in Cerrado sensu stricto protected against fire for 14 years (control) and in Cerrado sensu stricto submitted to a prescribed burning on August 26, 2008 (burned) in the Reserva Ecológica do IBGE, Brasilia-DF. The prescribed burning is represented by the black arrow and the beginning of the rainy season $(>10 \mathrm{~mm})$ in each period is represented by dashed arrows.

Revista Árvore, Viçosa-MG, v.36, n.4, p.685-693, 2012 


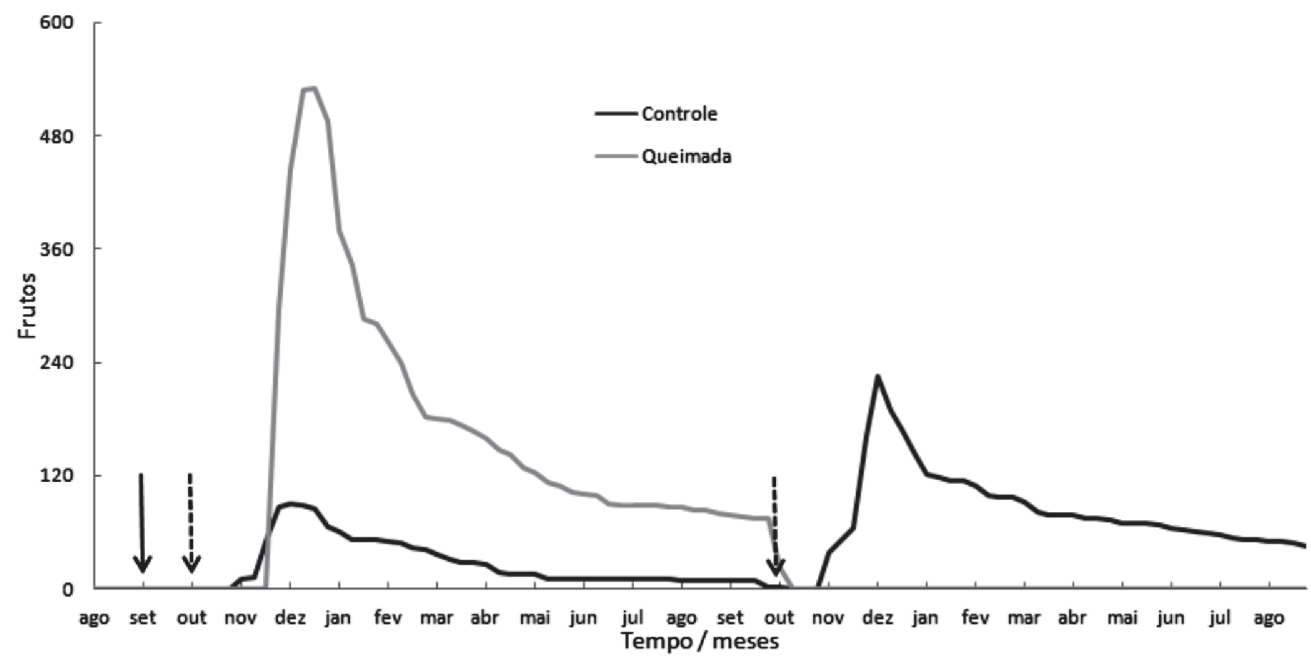

Figura 3 - Produção de frutos de Qualea parviflora de agosto de 2008 a agosto de 2010, em área de Cerrado sensu stricto protegida contra queima por 14 anos (controle) e em área submetida à queimada prescrita em 26 de agosto de 2008 (queimada), na Reserva Ecológica do IBGE, Brasília, DF. A queima está representada pela seta preta e o início da estação chuvosa ( $>10 \mathrm{~mm}$ ) em cada período, representado pelas setas pontilhadas.

Figure 3 -- Fruit production of Qualea parviflora from August 2008 to August 2010 in Cerrado sensu stricto protected against burning for 14 years (control) and and in Cerrado sensu stricto submitted to prescribed burning on August, 262008 (burned) in the Reserva Ecologica do IBGE, Brasília-DF. The prescribed burning is represented by the black arrow and the beginning of the rainy season $(>10 \mathrm{~mm})$ in each period is represented by dashed arrows.

Tabela 1 - Produção de botões, flores e frutos (média \pm erro-padrão) por ramos secundários de Qualea parviflora em área de Cerrado sensu stricto protegida contra queima por 14 anos (controle) e em área de Cerrado sensu stricto submetida à queimada prescrita em 26 de agosto de 2008 (queimada), na Reserva Ecológica do IBGE, Brasília, DF - "Fruit set" de botões para frutos $(\mathrm{B} / \mathrm{Fr})$ e flores para frutos $(\mathrm{F} / \mathrm{Fr})$. Letras maiúsculas comparam dois períodos de uma mesma área e letras minúsculas, duas áreas em um mesmo período. Valores seguidos de letras diferentes apresentam diferença significativa $(\mathrm{p}<0,05)$.

Table 1 - Production of floral buds, flowers and fruits (mean \pm standard error) for the secondary branches of Qualea parviflora in cerrado sensu stricto protected against fire for 14 years (control) and in cerrado sensu stricto submitted to a prescribed burning on August 26, 2008 (burned) in the Reserva Ecológica do IBGE, Brasília, DF -"Fruit set ": flower buds to fruits $(B / F r)$ and flowers to fruits $(F / F r)$. Capital letters compare two periods in the same area; lowercase letters compare two areas in the same period. Values followed by different letters are significantly different $(p<0.05)$.

\begin{tabular}{|c|c|c|c|c|}
\hline & \multicolumn{2}{|c|}{$2008 / 2009$} & \multicolumn{2}{|c|}{2010} \\
\hline & Controle & Queimada & Controle & Queimada \\
\hline Botões & $4,3 \pm 3,7$ a, $\mathrm{A}$ & $25,8 \pm 12,7 b$ & $14,5 \pm 5,9 \mathrm{~A}$ & - \\
\hline Flores & $1,2 \pm 1,3$ a, $\mathrm{A}$ & $7,1 \pm 4,1 \mathrm{~b}$ & $3,2 \pm 1,5$ & - \\
\hline Frutos & $1,0 \pm 0,9 \mathrm{a}, \mathrm{A}$ & $5,9 \pm 3,6 b$ & $17 \mathrm{~B}$ & - \\
\hline $\mathrm{B} / \mathrm{Fr}(\%)$ & $23 \mathrm{a}, \mathrm{A}$ & $23 \mathrm{a}$ & $17 \mathrm{a}$ & - \\
\hline $\mathrm{F} / \mathrm{Fr}(\%)$ & 85 a,A & $84 \mathrm{a}$ & $78 \mathrm{~B}$ & - \\
\hline
\end{tabular}

$\mathrm{n}=90$ ramos secundários.

Na estação reprodutiva seguinte, outubro de 2009 a agosto de 2010 , nenhum indivíduo marcado na área queimada produziu inflorescências, enquanto na controle nove iniciaram o ciclo reprodutivo, e um deles morreu cinco meses após o início das observações. Foram registrados 66 ramos secundários produzindo inflorescências. Nesse período, tanto o número de indivíduos florindo quanto o número de ramos

Revista Árvore, Viçosa-MG, v.36, n.4, p.685-693, 2012 
secundários com inflorescências foram significativamente maiores $\left(\mathrm{G}=10,238 ; \mathrm{X}^{2}=54,384 ; \mathrm{p}<0,05\right)$ do que no período anterior (2008/2009). Foram produzidos 1.307 botões, dos quais 290 (22\%) desenvolveram flores e a produção de frutos foi de 226 , representando $17 \%$ do total inicial de botões e $78 \%$ das flores (Tabela 1). Em relação ao período anterior (2008/2009), não houve diferença significativa ( $\mathrm{p}>0,05)$ entre as produções de botões e flores. No entanto, a produção de frutos no período de 2009/2010 foi significativamente maior $(p<0,05)$ do que no período de 2008/2009.

\section{DISCUSSÃO}

Embora a produção de botões, flores e frutos tenha sido maior na área queimada, o percentual de botões que desenvolvem flores (27\%) e frutos (23\%) foi o mesmo nas duas áreas, de outubro de 2008 a outubro de 2009. A maior parte dos botões iniciados foi perdida antes de desenvolver flores (73\%), no entanto a maior parte das flores produzidas desenvolveu frutos $(84 \%)$. Essa perda de botões pode ser uma estratégia, do ponto de vista energético, em investir em estruturas mais dispendiosas que resultem em frutos (SILVA, 1998). A respeito de Q. multiflora, Del-Claro et al. (1996) relataram que cerca de $48 \%$ dos botões iniciados desenvolveram frutos. Valor superior ao encontrado para $Q$. parviflora, indicando diferenças no investimento de recursos nas estruturas reprodutivas entre as duas espécies. Já para Rourea induta o "fruit set" de flores para frutos ficou entre $25 \%$ e $40 \%$, dependendo da morfologia floral (LENZA et al., 2008). Segundo esses autores, os valores de "fruit set" sugerem elevado potencial reprodutivo da espécie e que o serviço de polinização é eficaz, o que também pode ser verdade para $Q$. parviflora. Assim, tanto o "fruit set" de botões para frutos e de flores para frutos indicam elevado potencial reprodutivo de $Q$. parviflora, que parece não ser afetado na primeira estação reprodutiva pós-fogo. Embora alguns trabalhos relatem diminuição na produção de frutos em decorrência do menor número de polinizadores após uma queimada (FELFILI et al., 1999; MIOLA et al., 2010), em Q. parviflora não houve diferença significativa no percentual de frutos formados na área-controle e na área experimental após a queima. Tal fato sugere que os polinizadores de $Q$. parviflora não foram afetados pela queima e que, mesmo que a produção de botões e flores tenha sido estimulada pelo fogo, os polinizadores agiram de forma semelhante nas duas áreas. Entretanto, as inflorescências produzidas na área experimental cinco meses após o máximo de floração (Figuras 1 e 2) não resultaram em frutos (Figura 3), talvez pela falta de polinizadores na área, ou como consequência do gasto de recursos investidos na intensa floração pós-fogo e na reposição da parte vegetativa.

Uma floração mais intensa após um evento de queima tem sido reportada para espécies do estrato rasteiro do Cerrado (HADDAD; VALIO, 1993; MUNHOZ; FELFILI, 2005). Para espécies lenhosas e, ou, do estrato arbóreo do Cerrado, Miranda (1995), Silva et al. (1996), Hoffmann (1998), Benezar e Pessoni (2006) e Miola et al. (2010) relataram o efeito positivo do fogo na floração. A intensa floração observada após o fogo pode ser resultado da maior disponibilidade de luz e nutrientes, principalmente nitrogênio e cátions (KAUFFMAN et al., 1997). Além desses fatores, o início da estação chuvosa também pode contribuir para uma floração mais intensa funcionando como "gatilho" ambiental do início da floração (OLIVEIRA, 1998). Esse conjunto de fatores poderia explicar a diferença observada na intensidade da floração de Q. parviflora, entre as áreas-controle e experimental, no período reprodutivo seguinte à queimada. $\mathrm{O}$ começo da estação chuvosa marcou o início do ciclo reprodutivo nas duas áreas, no entanto havia na área experimental maior disponibilidade de luz e nutrientes em decorrência da queimada. No período reprodutivo seguinte (2009/2010), o início da estação chuvosa coincidiu novamente com o início do ciclo reprodutivo de $Q$. parviflora na área-controle, no entanto na área experimental os indivíduos não iniciaram seu ciclo reprodutivo. Embora tenha havido grande investimento em botões, flores e frutos imediatamente após a queima, houve também investimento para repor a parte vegetativa perdida durante a queimada, o que pode significar investimento das reservas e, portanto, ausência de flores na próxima estação reprodutiva. Padrão semelhante foi observado por Hoffmann (1998) em Piptocarpha rotundifolia, que apresentou alta produção após a queima e floração menos intensa até três anos após a queimada.

Segundo Silva (1998), Q. grandiflora tende a alternar períodos de alta produção de botões e flores com períodos de menor produção. Segundo Whelan (1995), espécies que apresentam esse tipo de padrão tendem a ser mais prejudicadas quando a queima ocorre 
em ano de maior produção, uma vez que a perda de estruturas reprodutivas será maior. Para $Q$. parviflora, essa alternância de produções foi observada na áreacontrole, onde a produção de botões, flores e frutos no período de 2008/2009 foi menor do que no período de 2009/2010. Nos indivíduos da área queimada, esse padrão não foi observado. A princípio, a queimada estimulou floração vigorosa. Entretanto, não houve produção de flores no ano seguinte, o que sugere que $Q$. parviflora pode necessitar de mais de um ano após a queima para retomar seu ciclo normal de reprodução, como reportado por Sanaiotti e Magnusson (1995) e Hoffmann (1998) a respeito de algumas espécies do Cerrado.

\section{CONCLUSÃO}

Dois meses depois da queimada prescrita, tanto os indivíduos de Qualea parviflora da área queimada quanto os da área-controle iniciaram a floração, entretanto os da área queimada apresentaram produção de flores e frutos significativamente maior do que aqueles da área-controle. Entretanto, mesmo com esse estímulo na floração não houve diferença significativa no "fruit set" entre as áreas, indicando que, apesar do aumento do esforço reprodutivo, não houve incremento na eficiência da formação de frutos.

A ausência de produção de flores nos indivíduos da área queimada um ano após a passagem da frente de fogo sugere que $Q$. parviflora pode necessitar de mais de um ano após a queima para retomar seu ciclo normal de reprodução. Dessa forma, a aplicação de técnicas de manejo com fogo que visam diminuir a biomassa do estrato rasteiro (combustível) deve considerar não só os efeitos imediatos causados pelo fogo, mas também aqueles de longo e de médio prazo, que podem alterar a taxa de recrutamento de novos indivíduos na área em manejo.

\section{AGRADECIMENTOS}

À CAPES, pela bolsa concedida a um dos autores; à Reserva Ecológica do IBGE, pela permissão para a realização do trabalho e pelo apoio logístico; em especial, aos integrantes da Brigada de Combate a Incêndios do IBGE, pela realização da queimada prescrita; e ao Departamento de Ecologia da Universidade de Brasília, pela disponibilização da infraestrutura utilizada nesta pesquisa.

\section{REFERÊNCIAS}

ANDRADE, L. A. Z.; MIRANDA, H. S. O fator fogo no banco de sementes. In: MIRANDA, H.S. Org. Efeitos do fogo sobre a estrutura de comunidades de Cerrado: resultados do Projeto Fogo. Brasília: IBAMA, 2010. p.103-119.

AQUINO, F. G.; WALTER, B. M. T.; RIBEIRO, J. F. Dinâmica de populações de espécies lenhosas de cerrado, Balsas, Maranhão. Revista Árvore, v.31, n.5, p.793-803, 2007.

BENEZAR, R. M. C.; PESSONI, L. A. Biologia floral e sistema reprodutivo de Byrsonima coccolobifolia (Kunth) em uma savana amazônica. Acta Amazonica, v.36, n.2, p.159-168, 2006.

BRAZ, V. S.; KANEGAE, M. F.; FRANCO, A. C. Estabelecimento e desenvolvimento de Dalbergia miscolobium Benth. em duas fitofisionomias típicas dos cerrados do Brasil Central. Acta Botanica Brasilica, v. 14, n.1, p.27-35, 2000.

BREWER, J. S. Geographic variation in flowering responses to fire and season of clipping in a fireadapted plant. The American Midland Naturalist, v.160, n.1, p.235-249, 2008.

COUTINHO, L. M. Ecological effects of fire in Brazilian Cerrado. In: HUNTLEY, B. J.; WALKER, B. H. (Eds.). Ecology of tropical savannas. Berlin: Springer-Verlag, 1982. p.273-291.

COUTINHO, L. M. Fire in the ecology of the Brazilian Cerrado. In: GOLDAMMER, J. G. (Ed.). Fire in the tropical biota - ecosystem processes and global challeges. Ecological Studies. Berlin: Springer-Verlag, 1990. p.82-105.

Del-CLARO, K.; BERTO, V.; RÉU, W. Effect ofherbivore deterrence by ants increase fruit set in an extrafloral nectar plant, Qualea multiflora (Vochysiaceae). Journal of Tropical Ecology, v.12, n. 6, p.887-892, 1996.

FELFILI, J. M. et al. Estudo fenológico de Stryphnodendron adstringens (Mart.) Coville no cerrado sensu stricto da Fazenda Água Limpa no Distrito Federal, Brasil. Revista Brasileira de Botânica, v.22, n.1, p.83-90, 1999.

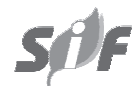

Revista Árvore, Viçosa-MG, v.36, n.4, p.685-693, 2012 
FIEDLER, N. C. et al. Efeito de incêndios florestais na estrutura e composição florística de uma área de cerrado sensu stricto na fazenda Água Limpa-DF.

Revista Árvore, v.28, n.1, p.129-138, 2004.

FREITAS, R. I. Abelhas silvestres (Hymenoptera: Apoidea) e a floração de plantas em áreas de Cerrado recém queimadas no Distrito Federal. 1998. 76 f. Dissertação (Mestrado em Ecologia) Universidade de Brasília, Brasília, 1998.

HADDAD, C. R. B.; VALIO, I. F. M. Effect of fire on flowering of Lantana montevidensis Briq. Journal of Plant Physiology, v.141, n.6, p.704-707, 1993.

HOFFMANN, W. A. Post-burn reproduction of woody plants in a neotropical savanna: the relative importance of sexual and vegetative reproduction. Journal of Applied Ecology. v.35, n.3, p.422-433, 1998.

HOFFMANN, W. A.; HARIDASAN, M. The invasive grass, Melinis minutiflora, inhibits tree regeneration in a Neotropical savanna. Austral Ecology, v.32, n.1, p.29-36, 2008.

KAUFFMAN, J. B.; SAPSIS, D. B.; TILL, K. M. Ecological studies of fire in sagebrush/bunchgrass ecosystems of the John Day Fossil Beds National Park, Oregon: implications for the use of prescribed burning to maintain natural ecosystems. Washington: National Park Service, Columbia Cascades System Support Office, 1997. (Technical Report NPS/CCSOSU/ NRTR-97/01)

LABOURIAU, L. G. et al. Nota sobre a germinação de sementes de plantas de cerrados em condições naturais. Revista Brasileira de Biologia, v.23, n.3, p. 227-237, 1963.

LANDIM, M. F.; HAY, J. D. Impacto do fogo sobre alguns aspectos da biologia reprodutiva de Kielmeyera coriácea Mart. Revista Brasileira de Biologia. v.56, n.1, p.127- 134, 1996.

LENZA, E. et al. Biologia reprodutiva de Rourea induta Planch. (Connaraceae), uma espécie heterostílica de cerrado do Brasil Central.

Revista Brasileira de Botânica, v.31, n.3, p.389-398, 2008.

Revista Árvore, Viçosa-MG, v.36, n.4, p.685-693, 2012
LOPES, S. F.; VALE, V. S.; SCHIAVINI, I. Efeito de queimadas sobre a estrutura e composição da comunidade vegetal lenhosa do cerrado sentido restrito em Caldas Novas, GO. Revista Árvore, v.33, n.4, p.695-704, 2009.

MAIN, M. B.; BARRY, M. J. Influence of season of fire on flowering of wet prairie grasses in South Florida, USA. Wetlands, v.22, n.2, p.430-434, 2002.

MEDEIROS, M. B.; MIRANDA, H. S. Post-fire resprouting and mortality in Cerrado woody plant specie. Edinburgh Journal of Botany, v.65, n.1, p.1-16, 2008.

MEDEIROS, M. B.; MIRANDA, H. S. Mortalidade pós-fogo em espécies lenhosas de campo sujo submetido a três queimadas prescritas anuais. Acta Botânica Brasilica, v.19, n.3, p.493-500, 2005.

MIOLA, D. T. B. et al. Efeito do fogo na fenologia de Syagrus glaucescens Glaz. ex Becc. (Arecaceae). Neotropical Biology and Conservation, v.5, n.3, p.146-153, 2010.

MIRANDA, H. S.; SATO, M. N. Efeitos do fogo na vegetação lenhosa do Cerrado. In: SCARIOT, A.; SOUSA-SILVA, J. C.; FELFILI, J. M. (Orgs.). Cerrado: ecologia, biodiversidade e conservação. Brasília, Ministério do Meio Ambiente, 2005. p.95-103.

MIRANDA, I. S. Fenologia do estrato arbóreo de uma comunidade de cerrado em Alter-do-Chão, Pará. Revista Brasileira de Botânica, v.18, n.2, p.235-240, 1995.

MIYANISHI, K.; KELLMAN, M. The role of fire in the recruitment of two neotropical savanna shrubs, Miconia albicans and Clidemia sericea. Biotropica, v.18, n.3, p.224-230, 1986.

MUNHOZ, C. B. R.; FELFILI, J. M.

Fenologia do estrato herbáceo-subarbustivo de uma comunidade de campo sujo na Fazenda Água limpa no Distrito Federal, Brasil. Acta Botânica Brasilica, v.19, n.4, p.979-988, 2005.

OLIVEIRA, P. E. Fenologia e biologia reprodutiva das espécies de Cerrado. In: SANO, S. M.; ALMEIDA, S. P. (Eds.). Cerrado ambiente e flora. Planaltina: 1998. p.169-192. 
OLIVEIRA, P. E.; SILVA, J. C. S. Reproductive biology of two species of Kielmeyera (Guttiferae) in the cerrados of Central Brazil. Journal of Tropical Ecology, v.9, n.1, p.67-79, 1993.

OLIVEIRA, P. E. A. M.; PAULA, F. R. Fenologia e biologia reprodutiva de plantas de Mata de Galeria. In: RIBEIRO, J. F.; FONSECA, C. E. L.; SOUSASILVA, J. C. (Eds.). Cerrado: caracterização e recuperação de matas de galeria. Planaltina: Embrapa-Cerrados, 2001.p.301-332,

PEREIRA, B. A., SILVA, M. A.; MENDONÇA, R. C. Reserva Ecológica do IBGE, Brasília (DF): lista de plantas vasculares. Rio de Janeiro: Fundação Instituto Brasileiro de Geografia e Estatística., 2004.

RIBEIRO, J. F.; HARIDASAN, M. Comparação fitossociológica de um cerrado denso e um cerrado em solos distróficos no Distrito Federal. In: CONGRESSO BRASILEIRO DE BOTÂNICA, 35., 1984, Manaus. Anais... São Paulo: Sociedade Brasileira de Botânica, 1984. p.342-353.

SANAIOTTI, T. M.; MAGNUSSON, W. E. Effects of annual fires on the production of fleshy fruits eaten by birds in a Brazilian Amazonian savanna. Journal of Tropical Ecology, v.11, n.1, p.53-65, 1995.

SATO, M. N. Efeito a longo prazo de queimadas na estrutura da comunidade de lenhosas da vegetação do cerrado sensu stricto. 2003. 84f. Tese (Doutorado em Ecologia) - Universidade de Brasília, Brasília, 2003.
SATO, M. N.; GARDA, A. A.; MIRANDA, H. S. Effects of fire on the mortality of woody vegetation in Central Brazil. In: VIEGAS, D. X. (Ed.). CONFERENCE ON FIRE AND FOREST METEOROLOGY, 14., Coimbra, 1998.

Proceedings... Coimbra, 1998.

Coimbra,University of Coimbra, Portugal, 1998. v.2. p.1777-1783.

SILVA, D. M. S. Comparação da Fenologia Reprodutiva de Qualea grandiflora (Vochysiaceae) em três áreas de cerrado sensu stricto. 1998. 44f. Dissertação (Mestrado em Ecologia) - Universidade de Brasília, Brasília, 1998.

SILVA, G. T.; SATO, M. N.; MIRANDA, H. S. Mortalidade de plantas lenhosas em um campo sujo de Cerrado submetido a queimadas prescritas. In: MIRANDA, H. S.; SAITO, C. H.; DIAS, B. F. S. (Orgs.) SIMPÓSIO IMPACTO DAS QUEIMADAS SOBRE OS ECOSSISTEMAS E MUDANÇAS GLOBAIS, 3.; CONGRESSO DE ECOLOGIA DO BRASIL. Anais... Brasília: 1996. p.93-101.

WHELAN, R. J. The ecology of fire. London: Cambridge University Press, 1995.

WROBLESKI, D. W.; KAUFFMAN, J. B. Initial effects of prescribed fire on morphology, abundance, and phenology of forbs in big sagebrush communities in southeastern Oregon. Restoration Ecology, v.11, n.1, p.82-90, 2003. 
